Karina Santistevan Villacreses, Adrián Valencia Medranda, Nathyn Collins Ventura, Lilia Valencia Cruzaty 


\title{
TASAS ACTIVAS Y PASIVAS EN LAS OPERACIONES BANCARIAS EN EL CANTÓN SALINAS DE LA PROVINCIA DE SANTA ELENA.
}

\author{
Karina Lourdes Santistevan Villacreses ${ }^{1}$, Adrián Valencia Medranda ${ }^{2}$, Nathyn Collins Ventura ${ }^{2}$, Lilia Valencia \\ Cruzaty $^{2}$. \\ ${ }^{1}$ Carrera de Comercio Exterior, Universidad Estatal del Sur de Manabí. \\ ${ }^{1}$ Carrera de Contabilidad y Auditoría, Universidad Estatal Península de Santa Elena. \\ E-mail:_kasanvill@hotmail.com
}

\begin{abstract}
Resumen
Las tasas de interés son fijadas por el Banco Central del Ecuador, sin embargo en el último lustro las tasas de interés activas y pasivas que ofrecen las instituciones financieras han sufrido ligeras modificaciones. Las tasas activas que imponen estos establecimientos superan en más de 10 puntos porcentuales a las pasivas, ubicándose en 15\% promedio. Esta situación hace que los usuarios de los bancos: Pichincha, Guayaquil, Pacífico, Bolivariano, entre otros, opten por retirar su dinero de las entidades antes mencionadas ya que los intereses que ellos reciben son muy bajos. El estudio situacional financiero en el cantón Salinas provincia de Santa Elena, obtuvo información a través de encuestas realizadas a los habitantes que son clientes, lográndose evidenciar las desventajas que pueden tener los usuarios.
\end{abstract}

Palabras Claves: Instituciones financieras, Tasas de interés, Créditos, Préstamos, Operaciones.

\begin{abstract}
Interest rates are set by the Central Bank of Ecuador, butin recent times the lending and deposit rates offered by financial institutions have been very high, around more than 10 percentage points to passive in lending rates, and $15 \%$ loans. This situation makes users of banks: Pichincha, Guayaquil, Pacifico, Bolivariano, choose to withdraw their money from them entities because the interest that they receive are not convenient. For this reason a financial situational study in the Province of Santa Elena is very important, we obtained accurate information through surveys that was undertaken to the inhabitants of that district, to get demonstrate the inconvenient for the users and using this information to inform to the public about the best alternatives when making a bank transaction.
\end{abstract}

Keywords: Financial Institutions, Interest Rates, Loans, Lendings.

K. Santistevan/A. Valencia/N. Collins/L. Valencia 


\section{Introducción.}

El desconocimiento de los usuarios de los tipos de tasas ajustables en el desarrollo de una operación bancaria y las tasas de interés representan un balance entre el riesgo y el posible lucro de la utilización de una cantidad de dinero en una situación y tiempo determinado.

En este sentido, la tasa de interés regula todas las transacciones bancarias crediticias y de ahorros entre los usuarios del servicio y la banca privada.

Según Pezo. L, (2008), Las instituciones financieras al realizar su función primordial de intermediación, incurren en gastos de operación, los mismos que inciden en la estructura de las tasas de interés. Si los bancos tienen altos gastos operativos, se estimula la tasa de interés activa al alza.

Entender esta información facilitaría a los usuarios la interpretación clara para diferenciar las tasas de interés en los diversos bancos que existen en la Provincia de Santa Elena.

\subsection{Tasas activas $y$ pasivas de las entidades bancarias.}

La actividad crediticia es vital para el desarrollo económico de un país, ya que facilita a los agentes económicos la adquisición de recursos para estimular la producción y el consumo de bienes y servicios.

En términos económicos, representa el precio del dinero en el mercado financiero o el porcentaje al que se ha invertido un capital en un período de tiempo. Las tasas de interés en las inversiones a un determinado plazo, es el principal incentivo que tienen los bancos para captar ahorros, los cuales ofrecen porcentajes "mínimos" con intereses en promedio del 4,5\% a las captaciones receptadas en plazos de un año.

Por ejemplo, en el Banco Pichincha, una inversión de 2.000 dólares a un año plazo obtiene un beneficio final de 80 dólares. Palabras del Sr. Bolívar Guerrero, quien agregó que en este banco (Pichincha) se paga el $4 \%$ en las pólizas, pero se cobra el $15,18 \%$ en los créditos que ofrecen.

En otra institución financiera como es el Banco del Pacífico, no es necesario ser cliente para acceder a créditos, los mismos que son otorgados con una tasa del $16,30 \%$.
En cambio en el Banco Guayaquil se cobra el 16,30\% a créditos de consumo y se paga 5,35\% a las inversiones de ahorro de los clientes.

\subsection{Influencias de las tasas activas y pasivas en las transacciones bancarias.}

El mercado financiero internacional es una de las principales fuentes de financiamiento de los sectores público y privado. Las tasas de interés internacionales representan una variable fundamental para la toma de decisiones financieras por parte de los inversionistas.

Una decadencia de las condiciones financieras en las instituciones bancarias es realizar sus operaciones relacionadas con su estabilidad económica, son las causas principales que atentan en lucro de cada cliente o usuario.

El aumento de las tasas de interés internacionales, dificultará el acceso de las transacciones mercantiles en el sector público y privado, al financiamiento externo, y a las tasas de interés domésticas. La tasa de interés representa el precio del dinero en el mercado financiero o el porcentaje al que se ha invertido un capital en un período de tiempo.

El exceso en el cobro de tarifas para el mantenimiento y actualizaciones de cuentas y uso de tarjetas, causa dificultades entre los clientes y restringe el uso de las tarjetas de débito y crédito. La falta de información en cuanto a las distintas tasas de interés que manejan las diferentes instituciones financieras afectan la toma de decisiones de cada usuario en el desarrollo de las operaciones financieras.

\subsection{Objetivo General.}

Evaluar la incidencia de las tasas activas y pasivas en las operaciones bancarias en el cantón Salinas de provincia de Santa Elena.

\section{Materiales y métodos.}

Para lograr los objetivos de la investigación se diseñó una encuesta realizada a 105 personas entre 18-58 años de edad de la Provincia de Santa Elena, mediante un muestreo probabilístico, la muestra es finita por eso se utilizó el muestreo aleatorio simple según (Mario. F, 2013).

Las entrevistas se efectuaron a los profesionales, con la finalidad de establecer criterios respecto al nivel gerencial y a los perfiles de desempeño. 
La importancia al momento de realizar alguna transacción bancaria permite conocer a los usuarios las ventajas y compromisos que adquieren con las instituciones financieras.

\subsection{Procesamiento y análisis.}

La información se procesó en función de las técnicas utilizada en la investigación. En lo que se refiere a la tabulación, se utilizó el programa estadístico SPSS 10.1 .

\section{Resultados.}

3.1 Instituciones bancarias que lideran las operaciones financieras en el cantón Salinas de la provincia de Santa Elena.

Los encuestados son clientes del Banco de Guayaquil, seguido de un gran porcentaje que registra operaciones financieras en el Banco Pichincha.

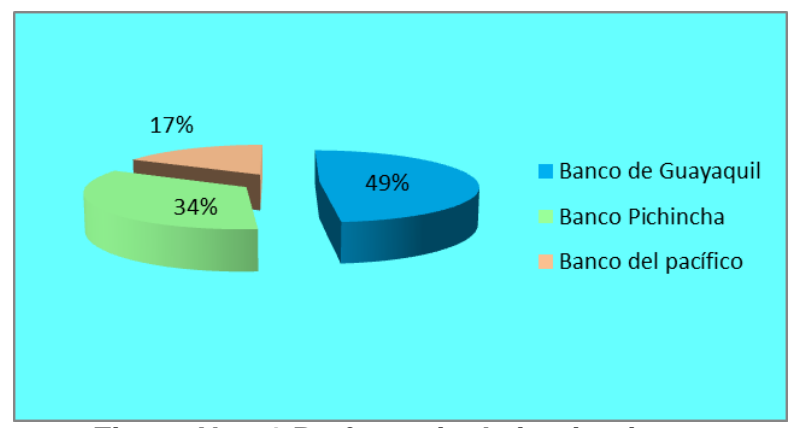

Figura No.- 1 Preferencia de instituciones financieras

\subsection{Perspectivas de las tasas de interés con que operan las instituciones financieras.}

La mayor parte de los encuestados considera que la tasa de interés con la que operan las instituciones financieras al realizar una operación de préstamo bancario es adecuada.

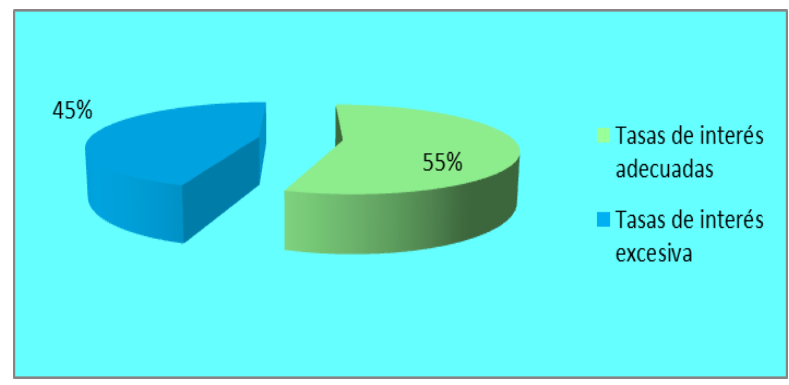

Figura No.- 2 Perspectivas de las tasas de interés

\subsection{Usuarios de instituciones bancarias que reciben asesoría sobre las tasas de interés.}

Como resultado de las encuestas realizadas se obtuvo que un $70 \%$ de los clientes de instituciones bancarias reciben asesoría sobre el costo del dinero en las operaciones financieras, y un $30 \%$ de los usufructuarios supieron manifestar que no reciben la adecuada asesoría de dichas operaciones.

\subsection{Tasas de interés que brindan las instituciones financieras en el mercado.}

Los tipos de tasas que se ofertan en el mercado financiero no son conocidas por los clientes, ya que como resultado de nuestro estudio se refleja que el 58\% de los clientes no diferencian el costo de dinero en sus respectivas operaciones y mientras que el $42 \%$ si poseen conocimientos acerca de este tema.

Es necesario que los usuarios de instituciones bancarias conozcan sobre la diferencia entre tasas activas y pasivas, puesto que genera una percepción negativa sobre los cálculos de tasas interés.

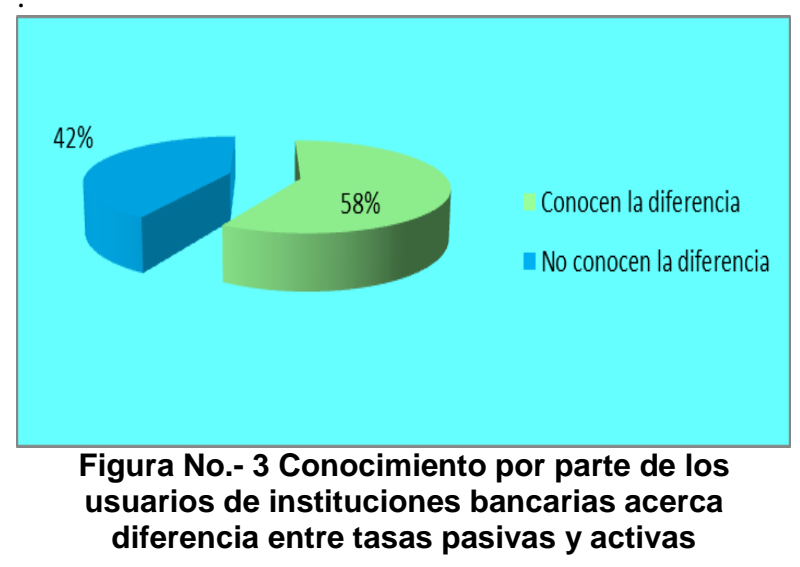

3.5 Importancia del conocimiento por parte de los usuarios de instituciones bancarias sobre los cálculos en las operaciones financieras.

El 91\% de los encuestados supo indicar que es importante el conocimiento de cómo se desarrollan los cálculos en las operaciones financieras para controlar su dinero, en un mínimo porcentaje que bordea el $9 \%$ se expresó con criterio personal que considera lo contrario, es decir que los funcionarios de la entidad saben cómo calculan las operaciones. Las instituciones bancarias deben brindar información suficiente $\mathrm{y}$ 
oportuna a los usuarios sobre lo cálculos de las tasas de interés, para el entendimiento adecuado de las operaciones financieras que realicen.

\section{Conclusiones.}

- Los consumidores tienen una limitada cultura respecto al costo del dinero en el tiempo por parte de las instituciones financieras y es apremiante hoy en día saber dónde pueden obtener réditos disminuyendo los riesgos por sus acciones o inversiones.

- Los usufructuarios no eligen en saber más de las tasas que tienen las otras instituciones financieras previo al mayor número de ahorro y depósitos realizados por la imagen y servicios de las entidades de su confianza.

- Los porcentajes de tasas activas que se cobran en los créditos dependen mucho del sector al que apuntan, sea este para empresas grandes o sector corporativo la tasa será más alta, que para microempresas, sector de consumo o microcréditos.

- Las instituciones que incurren en más gastos operativos en sus actividades de intermediación financiera con los clientes, propenden a que sus tasas de interés activas sean más altas.

\section{Referencias}

[1] Chiavenato, I. (2006). Introducción a la teoría general de la administración, 3ra ed. México. McGrawHill.

[2] Domínguez, M. (2011). Dirección Financiera y Gestión de Empresas. España. Editorial Vértice.

[3] Ecuatoriano, E. (20 de 03 de 1929). Superintendencia de Bancos del Ecuador. Recuperado el 12 de 08 de 2014, de Superintendencia de Bancos del Ecuador.

[4] Hill, C. (2000). Administración Estratégica. México. Pearson.

[5] Mendez, C. (2006). Metodología Diseño y Desarrollo del Proceso de Investigación con énfasis en
Ciencias Empresariales. 4ta. Edición. México. Editorial Limusa S.A.

[6] Orbe, G. (2012). boletín informativo de la Asociación de bancos privados del Ecuador. Recuperado el 10 de AGOSTO de 2014, de boletín informativo de la Asociación de bancos privados del Ecuador.

[7] Ortegón E., Pacheco J. y Roura H. (2005). Metodología general de Identificación, Preparación y evaluación de Proyectos de Inversión. Santiago de Chile.

[8] Paredes Wilson y Nataly. (2011). Investigación Acción. 1ra. Edición. Quito. Editorial Grijalba. 